\title{
Pengaruh Komponen Hidrofobik Elastis terhadap Karakteristik Fisik dan Laju Disolusi Tablet Eritromisin Stearat
}

(Impact of hydrophobic-elastic compound on physical characteristic and dissolution rate of erythromycin stearate tablet)

\author{
Diajeng Putri Paramita* \& Dwi Setyawan \\ Fakultas Farmasi Universitas Airlangga, Gedung Nanizar Zaman Joenoes, Kampus C J. Mulyorejo, \\ Surabaya, Jawa Timur, Indonesia
}

\begin{abstract}
Erythromycin stearate (ERS) is known for sintering phenomena during compression that can impact the dissolution profile. ERS tablets were prepared in binary mixture with paracetamol (PRS) and mefenamic acid (ASM) to examine the effect of the last two hydrophobic characteristics toward sintering of ERS. Physical characterization was performed using mechanical strength test, X-ray powder diffraction (XRPD), scanning electron microscope (SEM), differential thermal analysis (DTA), infrared spectrophotometry, and dissolution test. Tensile strength of ERS tablet was improved in presence of PRS and ASM that better improvement was shown by ASM. Superimposition of diffraction pattern of ERS with PRS or ASM was observed on XRPD diffractogram of binary tablet. SEM photomicrographs displayed particle boundaries on the surface of binary tablet of ERS-PRS and ERS-ASM. Infrared spectra and DTA thermograms did not exhibit any new or different peak due to interaction between compounds except for polymorphic transformation of PRS exhibited by thermogram data. Improvement of dissolution profile was shown by ERS-PRS binary tablet compared to ERS tablet. According to the results, it can be concluded that PRS and ASM can minimize sintering phenomena of ERS, and it does not involve any specific interaction. However, only PRS can improve dissolution of ERS tablet.
\end{abstract}

Keywords: erythromycin stearate; paracetamol; mefenamic acid; sintering; physical characterization; hydrophobic compound.

ABSTRAK: Eritromisin stearat (ERS) diketahui menunjukkan fenomena sintering ketika dikempa yang dapat memengaruhi profil disolusi sediaan tabletnya Pembuatan tablet campuran biner ERS dilakukan dengan komponen yang bersifat hidrofobik elastis yaitu parasetamol (PRS) dan asam mefenamat (ASM) untuk dipelajari pengaruhnya terhadap fenomena sintering dari ERS Karakterisasi fisik tablet campuran biner meliputi uji kekuatan mekanis, difraksi sinar-X serbuk (DSXS), scanning electron microscope (SEM), differential thermal analysis (DTA), spektrofotometri inframerah, dan terakhir dilakukan uji disolusi. Keberadaan PRS dan ASM meningkatkan nilai kekuatan tarik tablet ERS ASM memberikan peningkatan yang lebih tinggi. Superimposisi pola difraksi ERS dengan PRS maupun ASM teramati dari difraktogram sinar-X campuran biner. Fotomikrograf SEM memperlihatkan batas-batas antarpartikel pada permukaan dan patahan tablet campuran biner yang menunjukkan penghambatan sintering ERS Spektra inframerah dan termogram DTA tidak menunjukkan adanya puncak baru akibat interaksi pada sampel campuran biner, hanya mengindikasikan transformasi polimorfik dari PRS pada data termogram. Tablet campuran biner ERS-PRS menghasilkan profil disolusi lebih baik dari pada tablet ERS. Berdasarkan hasil karakterisasi dapat disimpulkan bahwa PRS dan ASM mampu mencegah fenomena sintering dari ERS tanpa berinteraksi secara spesifik dengan ERS, namun hanya PRS yang mampu meningkatkan profil disolusi ERS.

Kata kunci: eritromisin stearat; parasetamol; asam mefenamat; sintering; karakterisasi fisik; komponen hidrofobik.

\section{Pendahuluan}

Sediaan farmasi umumnya diproduksi dalam bentuk padat dan sebagian besar dijumpai sebagai sediaan tablet dan kapsul. Kualitas sediaan padat ini dipengaruhi faktor formulasi dan proses pembuatan, contohnya tahap pengempaan. Eritromisin stearat (ERS) merupakan salah satu contoh bahan aktif farmasi (BAF) yang jamak ditemui dalam sediaan tablet $[1,2]$.
ERS adalah garam asam stearat dari eritromisin, suatu antibiotika golongan makrolida dengan spektrum yang luas, dengan jumlah asam stearat berlebih, dan memiliki kelarutan dalam air praktis tidak larut [3]. Karakter fisikokimia ERS belum banyak dikaji, namun paparan energi mekanis telah dipelajari dapat mengubah karakteristik

\section{Article history}

Received: 04 Sep 2019 Accepted: 09 Des 2019 Published: 30 Des 2019

Access this article

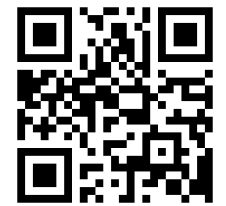


fisik ERS. Pengempaan pada berbagai gaya kompresi menyebabkan deformasi plastis pada ERS dan teramati fenomena sintering atau hilangnya batas-batas antarpartikel [2]. Fenomena ini memiliki efek yang kurang baik untuk sediaan tablet dengan pelepasan-segera karena akan memperlambat pelepasan BAF [4].

Tablet campuran biner ERS dengan komponen hidrofilik yang bersifat plastis pernah diteliti sebelumnya dan dari hasil karakterisasi disimpulkan bahwa keberadaan komponen hidrofilik tersebut memberikan pengaruh terhadap sintering yang dialami ERS selama pengempaan [2. 5]. Penelitian ini akan mengeksplorasi lebih lanjut sistem campuran biner ERS menggunakan komponen yang bersifat hidrofobik elastis dan dikaji karakteristik fisik tablet yang dihasilkan dan bagaimana pengaruhnya pada fenomena sintering ERS. Komponen hidrofobik elastis yang digunakan ialah BAF parasetamol (PRS) dan asam mefenamat (ASM). PRS merupakan adalah obat analgesik dan antipiretik populer yang dilaporkan tabletnya tidak stabil dan cenderung capping [6]. ASM termasuk golongan obat anti-inflamasi nonsteroid (OAINS) dan mempunyai sifat hidrofobisitas yang tinggi sehingga mempunyai kecenderungan menempel di area permukaan namun kompresibilitasnya cukup baik [7].

\section{Metode Penelitian}

\section{Bahan Penelitian}

Penelitian ini menggunakan bahan ERS, PRS, dan ASM yang merupakan hibah penelitian dari PT. Kimia Farma. ERS didapatkan dari Calyx Chemical \& Pharmaceuticals Pvft. Ltd., India; PRS diperoleh dari Hebei Jiheng Pharmaceutical Co. Ltd., Cina, sedangkan ASM berasal dari Shangyu Forever Chemical Co. Ltd., Cina.

\section{Metode Penelitian}

Tablet dibuat dari komponen tunggal ERS, PRS, dan ASM, maupun campuran biner ERS-PRS dan ERS-ASM dalam perbandingan bobot 70:30 (\% b/b). Serbuk ERS, PRS, dan ASM masing-masing diayak terlebih dahulu dengan pengayak bertingkat (Retsch AS-200, Jerman) untuk mendapatkan serbuk dengan ukuran partikel ratarata $425 \mu \mathrm{m}$. Untuk pembuatan campuran biner, ERS, PRS, dan ASM ditimbang sesuai dengan perbandingan bobotnya, kemudian setiap komposisi biner dicampur ringan dalam mortar selama 5 menit. Pengempaan dilakukan menggunakan die berdiameter $13 \mathrm{~mm}$ dan perangkat pengempa hidrolik Graseby-Specac (Jerman) pada beberapa gaya kompresi. Tablet yang dihasilkan selanjutnya dievaluasi kekuatan mekanis dan karakteristik fisik, serta uji disolusi.

\section{Uji Kekuatan Mekanis}

Komponen tunggal ERS serta campuran biner ERS-PRS dan ERS-ASM dikempa dengan berbagai gaya kompresi, yaitu 4,9; 9,8;14,7; 19,6; 24,5; dan 29,4 kN yang ditahan selama 3 detik. Masing-masing tablet diukur ketebalan dan diameternya, sedangkan kekerasan tablet diukur menggunakan alat hardness tester Erweka TB 24, Jerman. Kekuatan tarik dihitung melalui persamaan:

$$
\begin{aligned}
& \sigma=2 \mathrm{~F} / \pi \mathrm{D} \mathrm{t} \\
& \text { Keterangan: } \\
& \sigma=\text { kekuatan tarik }(\mathrm{kN} / \mathrm{cm} 2), \\
& \mathrm{F}=\text { kekerasan tablet }(\mathrm{kN}), \\
& \mathrm{D}=\text { diameter tablet }(\mathrm{cm}), \\
& \mathrm{t}=\text { ketebalan tablet }(\mathrm{cm}) .
\end{aligned}
$$

\section{Difraksi Sinar-X Serbuk (DSXS)}

Analisis difraksi sinar-X dilaksanakan pada suhu ruang menggunakan difraktometer Phillips XPert, Belanda. Sampel ditempatkan pada kamar sampel (sample holder) dan diratakan untuk mencegah orientasi habit kristal selama preparasi sampel. Kondisi pengukuran diatur sebagai berikut: sumber radiasi $\mathrm{CuK} \alpha$, rentang pembacaan $205-40^{\circ}$, pada voltase $40 \mathrm{kV}$ dan arus $30 \mathrm{~mA}$.

Scanning Electron Microscopy (SEM)

Morfologi permukaan dan patahan tablet diamati menggunakan perangkat SEM Jeol, Jepang. Sampel diletakkan pada kamar sampel dan dilapisi emas dengan ketebalan $10 \mathrm{~nm}$. Pengamatan dilakukan pada perbesaran 1000 kali yang diatur pada voltase $20 \mathrm{kV}$ dan arus $12 \mathrm{~mA}$.

\section{Differential Thermal Analysis (DTA)}

Analisis termal sampel dilakukan menggunakan instrumentasi DTA Mettler Toledo FP 85, Swiss, yang suhunya dikalibrasi dengan indium. Sampel sejumlah 5-7 mg ditempatkan dalam pan aluminium tertutup lalu dimasukkan ke dalam peranti DTA. Sampel dipanaskan pada rentang suhu $50-250^{\circ} \mathrm{C}$ dengan kecepatan pemanasan $10{ }^{\circ} \mathrm{C}$ per menit.

\section{Spektrofotometri Fourier Transform Infrared (FT-IR)}

Sampel dicampur dengan serbuk $\mathrm{KBr}$ pro spektrofotometri di dalam mortir hingga homogen, kemudian dimasukkan ke dalam alat pembuat cakram $\mathrm{KBr}$ dan ditekan dengan pompa hidrolik hingga diperoleh cakram yang transparan. Spektra inframerah diperoleh menggunakan spektrofotometer Spektrum One, Perkin Elmer (Amerika Serikat) pada rentang bilangan gelombang 
$450-4000 \mathrm{~cm}-1$

\section{Uji Disolusi}

Profil disolusi tablet komponen tunggal ERS, campuran biner ERS-PRS, dan ERS-ASM ditetapkan menggunakan instrumentasi Erweka DT 700 (Jerman) dengan metode USP II (tipe alat dayung) dan kecepatan pengadukan 100 putaran per menit. $900 \mathrm{~mL}$ dapar fosfat $\mathrm{pH}$ 6,8 digunakan sebagai medium disolusi dan suhu diatur pada $37 \pm 0,5^{\circ} \mathrm{C}$. Larutan sampel diambil pada interval waktu 15, 30, 60, 90 dan 120 menit sebanyak $7 \mathrm{~mL}$, kemudian segera diganti dengan medium disolusi dalam jumlah yang sama. Larutan sampel disaring melalui membran saring berdiameter pori $0,45 \mu \mathrm{m} .5 \mathrm{~mL}$ filtrat dimasukkan dalam labu ukur 25,0 mL, lalu ditambahkan $15 \mathrm{~mL}$ larutan $\mathrm{NaOH}$ 0,25 $\mathrm{N}$ dan digenapkan dengan dapar fosfat $\mathrm{pH} \quad 6,8$. Larutan ini kemudian dipanaskan dalam penangas air suhu $60{ }^{\circ} \mathrm{C}$ selama 5 menit. Larutan didinginkan terlebih dahulu sebelum diukur serapannya pada panjang gelombang eritromisin $(236 \mathrm{~nm})$ menggunakan spektrofotometer UVVis Cary-50 Conc, Varian (Amerika Serikat). Profil disolusi diekspresikan sebagai \% kadar terlarut eritromisin (data tiga kali replikasi) terhadap waktu.

\section{Hasil dan Diskusi}

\section{Kurva Kekuatan Tarik}

Kekuatan mekanis ERS tunggal dan campuran biner ERS-PRS dan ERS-ASM dijabarkan melalui kurva kekuatan tarik (Gambar 1). Kekuatan tarik merupakan ukuran ketahanan suatu komponen terhadap gaya kompresi sampai mengalami ruptur dan nilainya menggambarkan kemampuan komponen tersebut membentuk tablet yang baik atau tidak. Nilai kekuatan tarik dapat dihitung dari gaya yang diperlukan untuk memecah tablet (harga kekerasan) dan luas area yang diberi gaya kompresi (diameter tablet). Secara umum, peningkatan gaya kompresi akan meningkatkan nilai kekuatan tarik [8,9].

Tablet ERS memperlihatkan nilai kekuatan tarik paling rendah dibandingkan campuran binernya dan peningkatan gaya kompresi memberikan kenaikan nilai kekuatan tarik yang hampir tidak bermakna. Hal ini dapat disebabkan oleh fenomena sintering pada pengempaan ERS seperti kasus campuran biner ibuprofen-asam stearat [1]. Campuran biner ERS-PRS dan ERS-ASM menghasilkan tablet dengan nilai kekuatan tarik lebih tinggi, yang artinya adanya komponen kedua PRS dan ASM menunjukkan perbaikan karakter tabletasi dari ERS. Kekuatan tarik tertinggi ditunjukkan ERS-ASM karena hidrofobisitasnya yang memberinya karakter plastis, sementara PRS bersifat lebih elastis oleh karena struktur internal monoklinik dari polimorf bentuk I. Masalah capping yang sering terjadi dengan tablet PRS dapat disebabkan oleh kekakuan molekul di dalam struktur internal monoklinik [10].

Ketiga komponen menunjukkan pola yang sama, yaitu peningkatan nilai kekuatan tarik seiring naiknya gaya kompresi hingga titik tertentu, kemudian mengalami fase meluncur dan melewati batas wilayah deformasi plastis. Kristal menjadi getas (brittle) pada fase ini karena gaya kompresi yang tinggi sehingga tidak mampu mempertahankan strukturnya. Kurva kekuatan tarik pada Gambar 1 mendasari pemilihan tekanan 9,8 $\mathrm{kN}$ pada pengempaan tablet ERS beserta campuran binernya untuk karakterisasi fisikokimia dan uji disolusi. Nilai tersebut merupakan kompromi dari gaya kompresi yang memberikan kekuatan tarik tertinggi (tablet ERSASM sebelum fase meluncur) dan tidak berada pada fase meluncur (tablet ERS dan ERS-PRS belum mencapai nilai kekuatan tarik maksimum).

\section{Pola Difraksi Sinar-X Serbuk (DSXS)}

Pola difraksi sinar-X diperoleh untuk tablet ERS, PRS, ASM, campuran biner ERS-PRS dan ERS-ASM (70:30 $\% \mathrm{~b} / \mathrm{b}$ ). Tablet ERS memiliki difraktogram serbuk yang khas dibandingkan tablet PRS maupun ASM (Gambar 2A-C). PRS diketahui memiliki sejumlah polimorf: bentuk I stabil, bentuk II metastabil, bentuk III tidak stabil, dan belakangan ditemukan pula bentuk IV dan V dari PRS pada tekanan tinggi. PRS bentuk I adalah fasa yang paling stabil dan umum beredar di pasaran seperti yang digunakan pada penelitian ini $[11,12]$. ASM dilaporkan memiliki tiga polimorf yang dapat mengalami transformasi polimorfik oleh pengaruh suhu dan kelembaban. ASM bentuk I dan II berhubungan secara enantiotropik: bentuk I stabil pada suhu ruang dan berubah menjadi bentuk II yang stabil pada suhu tinggi, sedangkan bentuk III bersifat metastabil [13].

Tablet ERS-PRS memberikan superimposisi pola difraksi ERS dan PRS pada rentang $2 \theta$ yang diamati (Gambar 2D). Demikian pula dengan difraktogram tablet ERS-ASM yang karakter difraksi masing-masing komponen masih dapat teramati (Gambar 2E). Adanya interaksi di dalam campuran biner umumnya ditandai dengan perubahan pola difraksi pada difraktogram sinar-X serbuk, seperti muncul/hilangnya puncak baru dan pergeseran puncak [14]. Interpretasi difraktogram tablet campuran biner mengindikasikan paparan energi mekanis pada pengempaan ERS-PRS dan ERS-ASM tidak menyebabkan transformasi polimorfik maupun interaksi 
lainnya. Penurunan intensitas puncak difraksi umumnya dikaitkan dengan penurunan kristalinitas komponen [15], namun intensitas puncak ERS yang lebih rendah pada difraktogram tablet campuran biner lebih disebabkan oleh sampel yang berupa campuran sehingga mengurangi proporsi masing-masing komponen murninya. Studi pendahuluan yang dilakukan menunjukkan bahwa pengempaan ERS pada berbagai gaya kompresi tidak memengaruhi intensitas puncak difraksi (data tidak ditampilkan).

\section{Fotomikrograf SEM}

Analisis SEM dilakukan terhadap tablet ERS dan campuran biner ERS-PRS dan ERS-ASM (70:30 \% b/b) yang dikompresi pada tekanan $9,8 \mathrm{kN}$. Fotomikrograf yang diperoleh ditampilkan pada Gambar 3. Hilangnya batas antarpartikel teramati pada morfologi tablet ERS (Gambar $\underline{\text { 3A-B) }}$ yang menandakan terjadinya fenomena sintering. Salah satu perilaku mekanis dari ERS yang telah diketahui ialah mengalami sintering pada pengempaan, bahkan pada gaya kompresi serendah 4,9 kN [2]. Fenomena yang sama teramati pada fotomikrograf tablet ERS-PRS (Gambar $\underline{\text { 3C-D) }}$, namun masih nampak batas-batas antarpartikel di beberapa tempat. Keberadaan PRS diduga menghambat meleburnya batas antarpartikel ERS. Morfologi tablet ERS-ASM memperlihatkan batas antarpartikel yang lebih jelas dan memiliki lebih banyak pori-pori dibandingkan tablet ERS-PRS dan ERS (Gambar 3E-F). Ini berarti sintering partikel ERS terjadi pada area yang lebih sempit, dengan kata lain, ASM lebih bai $\mathrm{k}$ dalam mencegah fenomena sintering pada ERS [16].

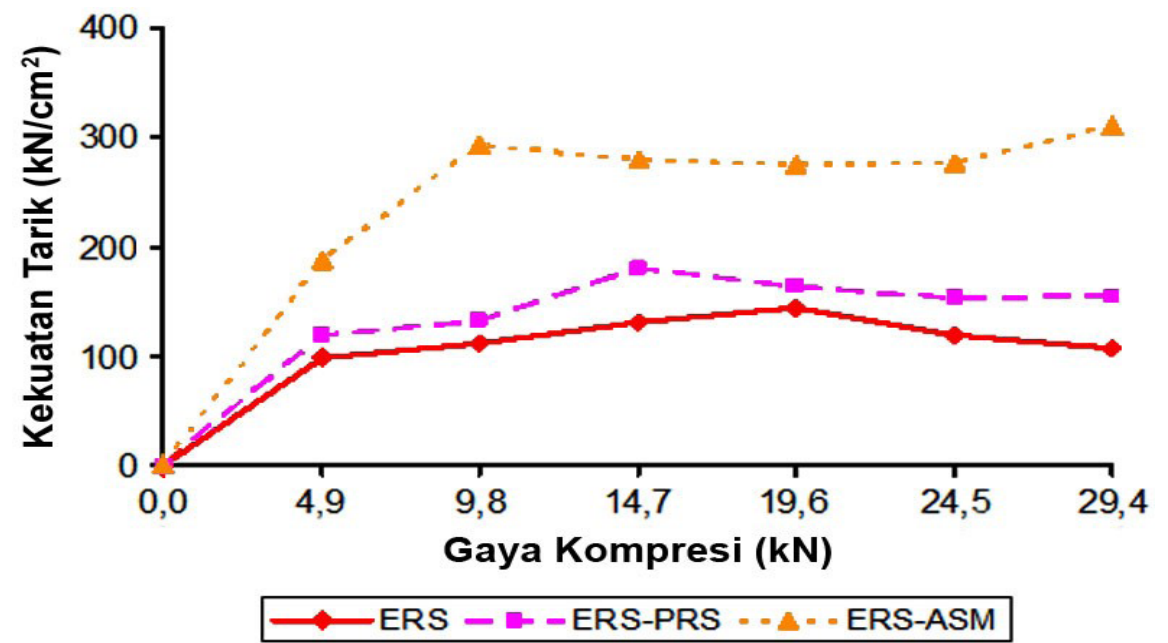

Gambar 1. Kurva kekuatan tarik ERS tunggal dan campuran biner ERS-PRS dan ERS-ASM (70:30 \% b/b)

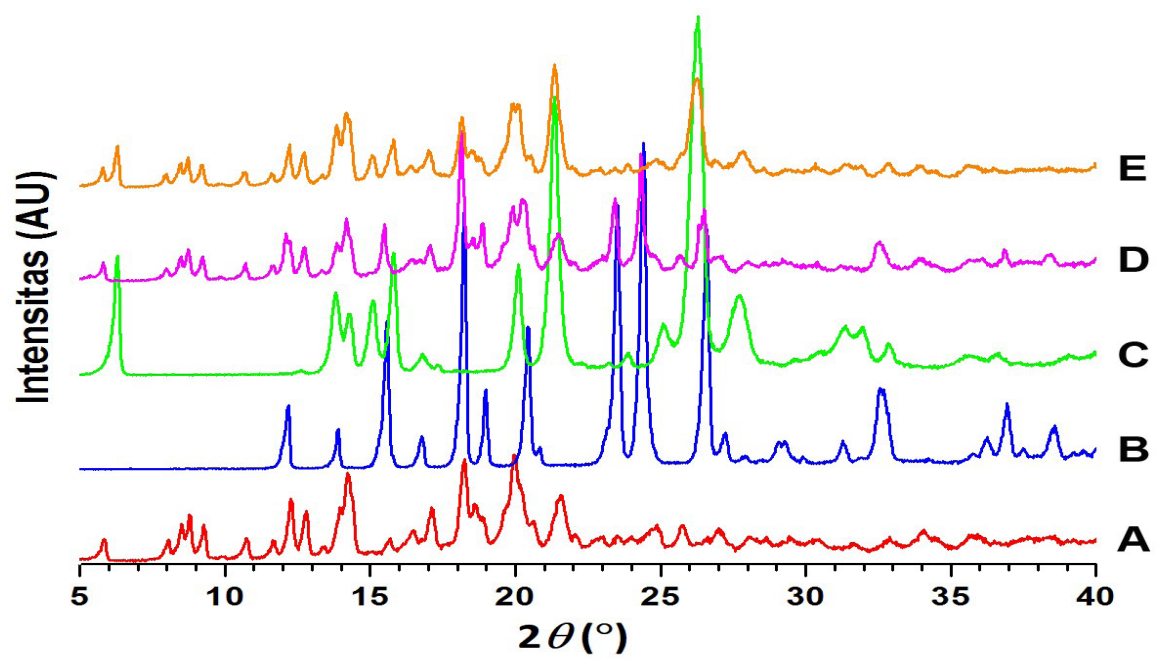

Gambar 2. Difraktogram sinar-X serbuk tablet (A) ERS, (B) PRS, (C) ASM, (D) ERS-PRS, dan (E) ERS-ASM 

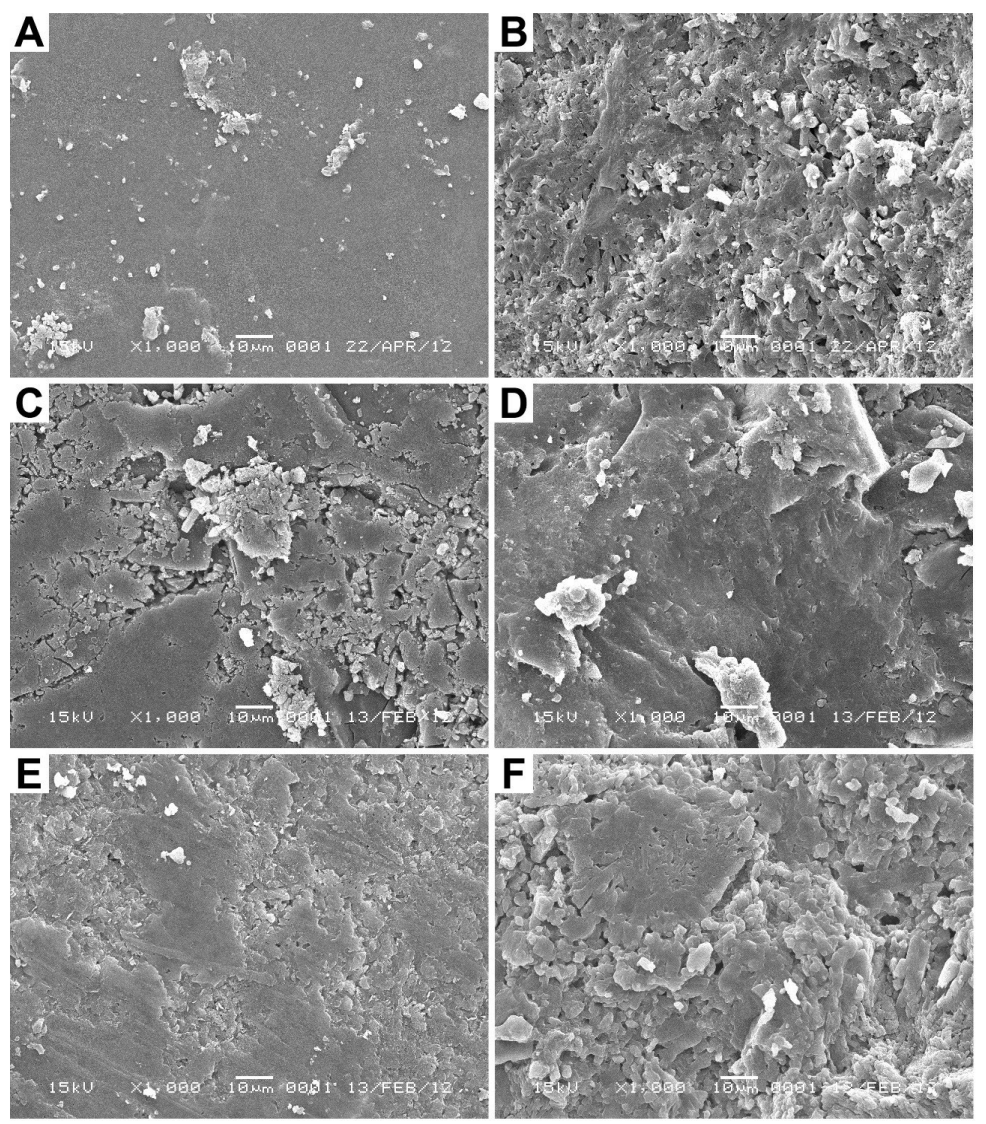

Gambar 3. Fotomikrograf SEM tablet (A) ERS (permukaan), (B) ERS (patahan), (C) ERS-PRS (permukaan), (D) ERS-PRS (patahan), (E) ERS-ASM (permukaan), dan (F) ERS-ASM (patahan) pada perbesaran 1000 kali

\section{Analisis Termal DTA}

Analisis termal menggunakan DTA dilakukan untuk mengidentifikasi interaksi yang terjadi antara ERS dengan PRS maupun dengan ASM. Campuran biner ERS-PRS dan ERS-ASM dibuat pada beberapa perbandingan berat, yaitu 10:90, 30:70, 50:50, 70:30, dan 90:10. Termogram ERS dan PRS memberikan puncak endotermik tunggal yang menunjukkan titik lebur keduanya berturut-turut pada suhu 112,8 dan $171,8{ }^{\circ} \mathrm{C}$ (titik lebur bentuk I) [2, 11]. Sedangkan ASM memiliki dua puncak endotermik pada $172,2^{\circ} \mathrm{C}$ yang merupakan suhu transisi fasa enantiotropik dan $232,7{ }^{\circ} \mathrm{C}$ dari peleburan bentuk II [13]. Termogram kedua campuran biner menunjukkan karakter endotermik masing-masing komponen yang diamati. Campuran biner ERS-PRS 50:50 (\% b/b) menghasilkan termogram dengan puncak endotermik khas dari ERS dan PRS serta puncak endotermik di dekat suhu $140{ }^{\circ} \mathrm{C}$. Puncak endotermik ini menandai bentuk II dari PRS, dengan demikian diduga terjadi transformasi polimorfik PRS pada tablet campuran biner. Transformasi polimorfik ini tidak teramati pada difraksi sinar-X serbuk dikarenakan puncak difraksi spesifik bentuk II berimpitan dengan bentuk I dan campuran kedua bentuk menyebabkan pelebaran puncak [11]. Campuran biner ERS-ASM 50:50 (\% b/b) memiliki puncak endotermik pada 106,1; 169,8; dan 203,8 ${ }^{\circ} \mathrm{C}$ yang teramati sebagai titik lebur masing-masing ERS dan ASM yang mengalami pergeseran pada tingkat yang lebih ekstrim (Gambar 5). Keberadaan komponen kedua telah dipelajari dapat menyebabkan transformasi polimorfik dan pergeseran titik lebur komponen pertama [17]. Hasil karakterisasi dengan DTA mengindikasikan tidak ada interaksi yang terbentuk antara ERS-PRS maupun ERSASM.

\section{Spektrofotometri F'TIR}

Identifikasi interaksi antara dua komponen dapat pula dilakukan melalui analisis inframerah. Spektra FTIR ERS, PRS, ASM, campuran biner ERS-PRS dan ERS-ASM (70:30\% b/b) dapat diamati pada Gambar 6. Spektrum inframerah dari ERS memperlihatkan pita serapan lebar khas ikatan -OH pada bilangan gelombang 3600-3100 cm-1. Pita serapan ikatan $\mathrm{C}=\mathrm{O}$ muncul pada dua bilangan 
gelombang, yaitu 1726 (ester pada lakton) dan $1710 \mathrm{~cm}-1$ (keton). PRS memiliki spektrum inframerah dengan pita serapan ikatan $\mathrm{N}-\mathrm{H}$ dan $\mathrm{C}=\mathrm{O}$ amida pada bilangan gelombang 3326 dan 1654 cm-1, secara berturut-turut, sedangkan pita serapan ikatan O-H keluar pada bilangan gelombang sekitar $3200 \mathrm{~cm}-1$. Dari analisis spektrum FTIR ASM didapatkan pita serapan ikatan N-H pada bilangan gelombang $3311 \mathrm{~cm}-1$ dan $\mathrm{C}=\mathrm{O}$ (karboksilat) pada 1650 cm-1. Ikatan O-H dari gugus karboksilat ditunjukkan dengan adanya pita serapan yang lebar pada bilangan gelombang 3200-2800 cm-1 [18]. Spektra inframerah campuran biner ERS-PRS dan ERS-ASM tidak menunjukkan perubahan pita serapan, melainkan hanya superimposisi serapan ERS dengan PRS maupun dengan ASM (Gambar 6). Superimposisi pita serapan inframerah ini mengindikasikan bahwa tidak ada interaksi yang terjadi antara ERS dengan PRS dan ASM.

\section{Profil Disolusi}

Gambar 7 menyajikan profil disolusi tablet ERS dan campuran biner ERS-PRS dan ERS-ASM (70:30\% b/b) yang dikompresi pada tekanan 9,8 kN. Efisiensi disolusi menit ke-120 (ED $\left.{ }_{120}\right)$ tablet ERS, ERS-PRS, dan ERS-ASM berturut-turut sebesar 7,1 $\pm 2,2 ; 12,7 \pm 0,1$; dan $4,4 \pm 0,2 \%$. Profil disolusi dan data $\mathrm{ED}_{120}$ menunjukkan bahwa PRS sedikit meningkatkan laju disolusi dari ERS, sementara laju disolusi ERS cenderung tidak dipengaruhi oleh ASM. Hasil uji disolusi tidak sesuai dengan evaluasi kekuatan mekanis dan karakterisasi SEM yang memperkirakan ASM lebih baik dalam meningkatkan laju disolusi ERS dibandingkan PRS. Fenomena sintering dapat berakibat pada penurunan laju disolusi karena meleburnya partikel-partikel ERS akan mengurangi luas area kontak medium disolusi dengan komponen itu sendiri [4]. ASM memberikan hambatan sintering lebih baik dibandingkan PRS, namun sifat hidrofobik ASM dan kelarutannya yang rendah dalam air nampaknya lebih berperan dalam profil disolusi yang dihasilkan. PRS memiliki kelarutan dalam air lebih tinggi $(0,014 \mathrm{~g} / \mathrm{mL}$ dibandingkan $0,008 \mathrm{~g} / \mathrm{mL}$ milik ASM) $[19,20]$ sehingga meski lebih rendah menghambat sintering partikel ERS, keberadaan PRS dapat meningkatkan disolusi tablet ERS lebih baik dari ASM.

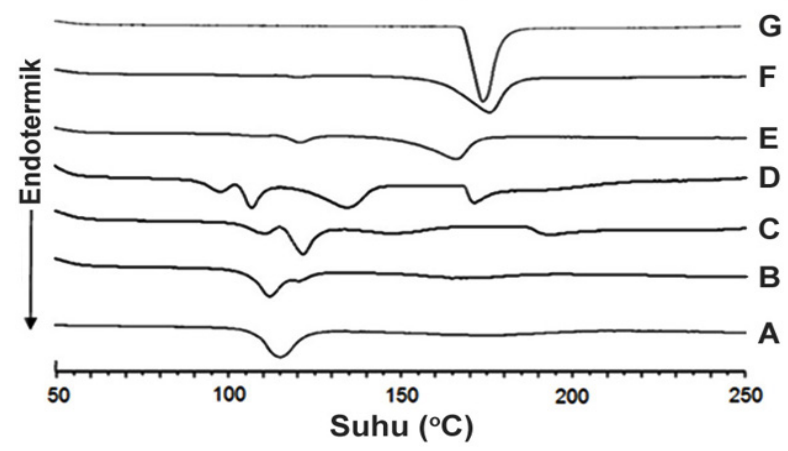

Gambar 4. Termogram DTA (A) ERS, campuran biner (\% b/b) ERS-PRS (B) 90:10, (C) 70:30, (D) 50:50, (E) 30:70, (F) 10:90, dan (G) PRS

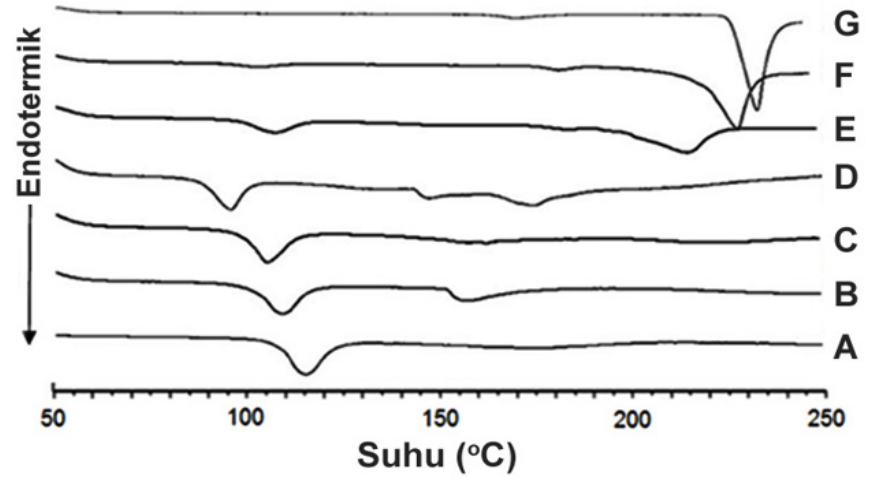

Gambar 5. Termogram DTA (A) ERS, campuran biner (\% b/b) ERS-ASM (B) 90:10, (C) 70:30, (D) 50:50, (E) 30:70, (F) 10:90, dan (G) ASM 


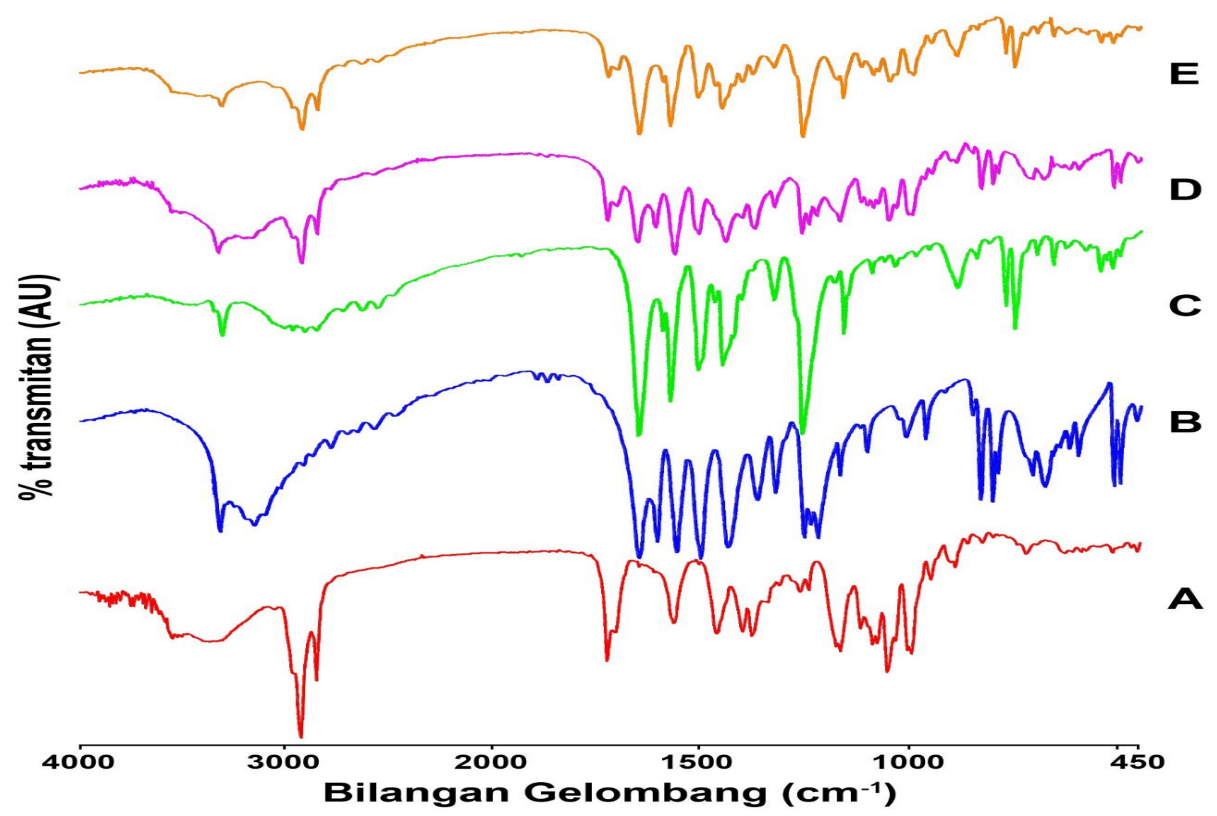

Gambar 6. Spektra FTIR (A) ERS, (B) PRS, (C) ASM, (D) ERS-PRS, dan (E) ERS-ASM

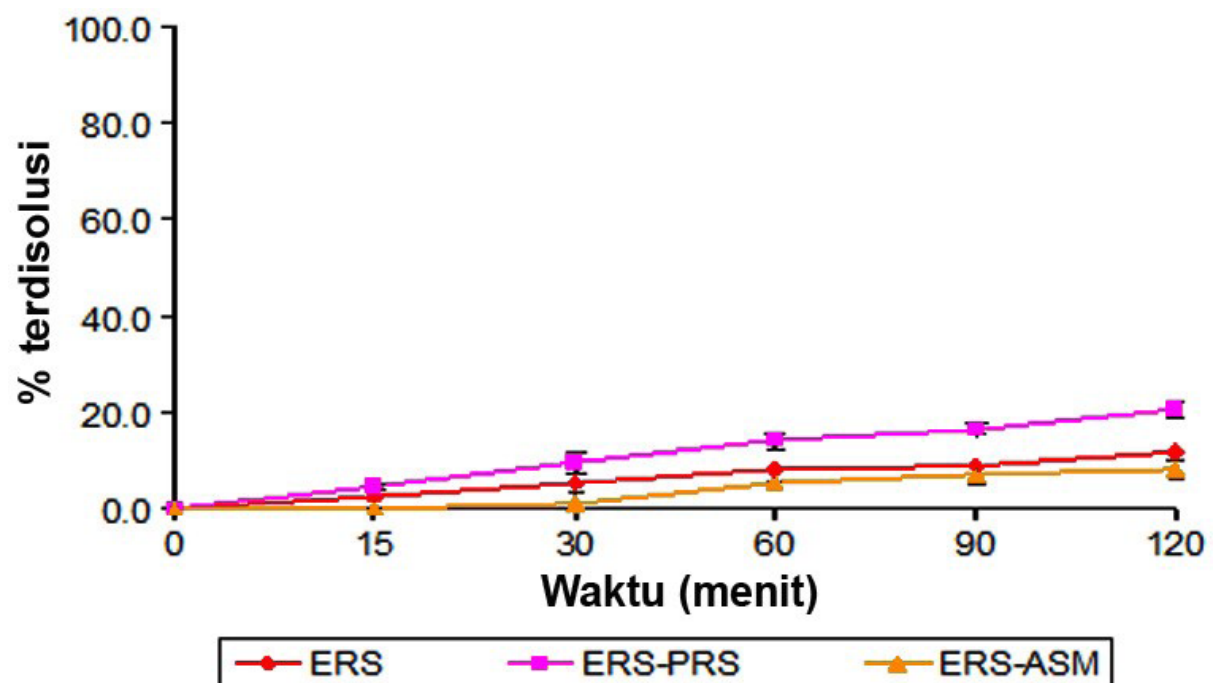

Gambar 7. Profil disolusi tablet ERS, ERS-PRS, dan ERS-ASM pada dapar fosfat pH 6,8 dan suhu $37+0,5^{\circ} \mathrm{C}$

\section{Kesimpulan}

Komponen bersifat hidrofobik dan elastis yang ditambahkan dalam komposisi 70:30 (\% b/b) terhadap ERS mampu menghambat terjadinya sintering pada ERS oleh karena pengempaan. ASM yang bersifat hidrofobik mencegah fenomena sintering lebih baik daripada PRS yang bersifat elastis. Meskipun demikian, ASM tidak lebih baik dari PRS dalam memperbaiki profil disolusi tablet ERS yang kemungkinan disebabkan oleh kelarutan ASM yang rendah di dalam air dan sifat sangat hidrofobik. Hal ini mengindikasikan bahwa memperbaiki disolusi ERS yang rendah akibat sintering tidak hanya mempertimbangkan kemampuan komponen kedua mencegah sintering melainkan juga tingkat kelarutannya.

\section{Referensi}

[1] Setyawan, D., Isadiartuti, D., Betari, S. D., \& Paramita, D. P. (2016). Physical characterization of ibuprofen-stearic acid binary mixture due to compression force. Indonesian Journal of Pharmacy, 27(1), 28-34. 
[2] Setyawan, D., Sumirtapura, Y. C., Soewandhi, S. N., \& Hadi, D. Tj. (2011). Karakterisasi sifat fisik sistem biner eritromisin stearatsodium starch glycolate akibat pengaruh tekanan kompresi. Majalah Farmasi Indonesia, 22(1), 43-49.

[3] Kemenkes Republik Indonesia. (2014). Farmakope Indonesia V. Jakarta: Kemenkes RI.

[4] Rao, M. R. P., Ranpise, A. A., Thanki, K. C., Borate, S. G., \& Parikh, G. N. (2009). Effect of processing and sintering on controlled release wax matrix tablets of ketorolac tromethamine. Indian Journal of Pharmaceutical Sciences, 71(5), 538-544.

[5] Setyawan, D., Sumirtapura, Y. C., Soewandhi, S. N., \& Hadi, D. Tj. (2012). Characterization of physical properties and dissolution rate of binary systems erythromycin stearate-microcrystalline cellulose and spray dried lactose due to compression forces. International Journal of Pharmacy and Pharmaceutical Sciences, 4(1), 652-657.

[6] Rasenack, N. \& Müller, B. W. (2002). Crystal habit and tableting behavior. International Journal of Pharmaceutics, 244, 45-57.

[7] Cesur, S. \& Gokbel, S. (2008). Crystallization of mefenamic acid and polymorphs. Crystal Research \& Technology, 43(7), 720-728.

[8] Hayashi, Y., Oishi, T., Shirotori, K., Marumo, Y., Kosugi, A., Kumada, S., Hirai, D., Takayama, K., \& Onuki, Y. (2018). Modeling of quantitative relationships between physicochemical properties of active pharmaceutical ingredients and tensile strength of tablets using a boosted tree. Drug Development and Industrial Pharmacy, 44(7), 1090-1098.

[9] Juban, A., Briancon, S., Puel, F., Hoc, T., \& Nouguier-Lehon, C. (2017). Experimental study of tensile strength of pharmaceutical tablets: effect of the diluent nature and compression pressure. Powders and Grains 2017 - 8th International Conference on Micromechanics on Granular Media, EPJ Web Conferences, 140, 13002.

[10] Martino, P. D., Guyot-Hermann, A., Conflant, P., Drache, M., \& Guyot, J. (1998). A new pure paracetamol for direct compression: the orthorhombic from. International Journal of Pharmaceutics, 128(12), 1-8.

[11] Wang, I. C., Lee, M. J., Seo, D. Y., Lee, H. E., Choi, Y., Kim, W. S., Kim, C. S., Jeong, M. Y., \& Choi, G. J. (2011). Polymorph transformation in paracetamol monitored by in-line NIR spectroscopy during a cooling crystallization process. AAPS PharmSciTech, 12(2), 764-770.
[12] Smith, S. J., Bishop, M. M., Montgomery J. M., Hamilton, T. P., \& Vohra, Y. K. (2014). Polymorphism in paracetamol: evidence of additional forms IV and $V$ at high pressure. The Journal of Physical Chemistry A, 118(31), 6068-6077.

[13] SeethaLekshmi, S. \& Guru Row, T. N. (2012). Conformational polymorphism in a non-steroidal anti-inflammatory drug, mefenamic acid. Crystal Growth \& Design, 12(8), 4283-4289.

[14] Zaini, E., Halim, A., Soewandhi, S. N., \& Setyawan, D. (2011). Peningkatan laju pelarutan trimetoprim melalui metode kokristalisasi dengan nikotinamida. Jurnal Farmasi Indonesia, 5(4), 205212.

[15] Setyawan, D., Widjaja, B., \& Sari, R. (2013). Study on crystallinity and compactibility of binary mixture of analgesic substances with microcrystalline cellulose. International Journal of Pharmacy and Pharmaceutical Sciences, 5(3), 784-789.

[16] Setyawan, D., Rosita, N., Paramita, D. P., \& Pratama, D. (2018). Penghambatan interaksi eutektik akibat energi kompresi dengan penambahan pati jagung. Jurnal Sains Farmasi \& Klinis, 5(1), 17-22.

[17] Hernández Espinell, J. R., López-Mejías, V., Stelzer, T. (2018). Revealing polymorphic phase transformations in polymer-based hot melt extrusion processes. Crystal Growth \& Design, 18(4), 19952002.

[18] Pavia, D. L., Lampman, G. M. \&amp; Kriz, G. S. (2001). Introduction to spectroscopy 3rd edition. Washinton: Thomson Learning.

[19] Noviza, D., Febriyanti, N., \& Umar, S. (2015). Solubilsasi parasetamol dengan Ryoto ${ }^{\circledR}$ Sugar Ester dan propilen glikol. Jurnal Sains Farmasi \& Klinis, 1(2), 132-139.

[20] Iskandarsyah, M. P. (2010). Preparasi dan karakterisasi nanosuspensi dengan polivinilpirolidon (PVP) sebagai pembawa nanopartikel senyawa asam mefenamat. Majalah IImu Kefarmasian, VII(2), 52-61

Copyright $\odot 2019$ The author(s). You are free to share (copy and redistribute the material in any medium or format) and adapt (remix, transform, and build upon the material for any purpose, even commercially) under the following terms: Attribution - You must give appropriate credit, provide a link to the license, and indicate if changes were made. You may do so in any reasonable manner, but not in any way that suggests the licensor endorses you or your use; ShareAlike - If you remix, transform, or build upon the material, you must distribute your contributions under the same license as the original (https://creativecommons. org/licenses/by-sa/4.0/) 